\title{
Produktive Synthese. Das romantische Drama zwischen Anverwandlung der Tradition und Innovation der Form
}

Internationale Tagung in Karlsruhe, 12.-15. September 1999

Die Aktualität der Romantik steht außer Frage. Dies zeigt nicht zuletzt die Vielzahl an literaturwissenschaftlichen Neuerscheinungen, die sich mit der romantischen Literatur und ihrem Umfeld in ganz unterschiedlicher methodischer Perspektivierung beschäftigen. Der einschlägige Kanon von Autoren und Texten ergibt sich dabei aus der Orientierung am Roman als dem romantischen Buch, wie sie bekanntlich von der frühromantischen Theorie profiliert wurde. Genauer untersucht sind demnach Formen romantischer Prosa vom Kunstmärchen bis zum Universalroman sowie - über deren Musikalisierung die romantische Lyrik. Die dramatische Produktion romantischer Autoren dagegen wurde literarhistorisch bisher noch nicht systematisch gewürdigt.

Die Tagung macht es sich deshalb zur Aufgabe, das Spektrum des romantischen Dramas im Kontext abzustecken. Der Zugang soll in doppelter Perspektivierung erfolgen: Überblicksdarstellungen zu Fragen der Epochalisierung oder zur Gattungstheorie sind ebenso erwünscht wie Einzelbetrachtungen zu Autoren, zu intertextuellen Bezügen oder zur Wirkungsgeschichte.

Interessenten aus dem In- und Ausland werden gebeten, ihre Themenvorschläge mit kurzem Exposé von ca. 30 Zeilen bis zum 31. Mai 1998 einzureichen. Für die Tagung wird ein Zuschuß beantragt. Referenten sollen Reise- und Unterbringungskosten erstattet werden. Die Tagungsbeiträge sollen eine Länge von 45 Minuten nicht überschreiten. Rückfragen, Themenvorschläge und Exposés sind zu richten an:

Prof. Dr. Uwe Japp

Universität Karlsruhe

Institut für Literaturwissenschaft

Postfach 6980

76128 Karlsruhe

Tel. (0721) 60821 50/1

Fax (0721) 6084778 